\title{
Investigating Life Skills among Young Students in Malaysia
}

\author{
Sakineh Mofrad, Kwan Foong Chee, Andrea Emmanuel Koh, and Ikechukwu Uba
}

\begin{abstract}
The study examined the life-skills perception of freshmen undergraduate students. The respondents of the survey were 500 young adults aged 18 to 25 years from selected universities in Subang Jaya, Malaysia. Life-skills Development Inventory-College Form was used to measure life skills in four domains: interpersonal communication, decision making, health maintenance and identity development. The finding revealed significant gender difference in health maintenance. Recommendations of the study underscored the relevance of the findings in interventions and skills building activities.
\end{abstract}

Index Terms-Life-skills development, interpersonal communication, young adult.

\section{INTRODUCTION}

Growing up is a difficult task for both late adolescents and young adult. At this stage, decisions regarding education, career, finding a partner and whether to build a family are made [1]. This period is considered most stressful, given inherent challenges that may alter their life journey. Hence, it is vital that students are occupied with optimum skills necessary in their adaptation to new life [1]. At this period, young adults start their separation from family, with the view of developing identity. They become more independent by creating their own goals and decisions for life.

According to the World Health Organization [2], individuals with adequate life skills adapt and have positive behaviors in dealing with the challenges and demands of everyday life. Skilled young adults are able to form relationships in their social contexts necessary in widening their social spectrum and intimacy [1]; furthermore, WHO [3] singled out low academic achievement, poor social competence, poverty, truancy and impulsiveness as risk factors for violence among individuals. By developing life skills, social and emotional skills can help young adults manage their life better.

Based on Brooks [4] taxonomy of developmental life-skills, Picklesimer [5] classified generic life-skills into four main categories. The first category was Interpersonal Communication/Human Relations Skills (IPC/HR) related to

Manuscript received March 8, 2013; revised April 30, 2013. This work was supported by the internal research grant from Sunway University, Malaysia.

Sakineh Mofrad and Chee Kwan Foong are with the Psychology Department, Sunway University, Petaling Jaya, 46150, Malaysia (e-mail: sakinehm@sunway.edu.my, kwanfoongc@sunway.edu.my).

Andrea Emmanuel Koh is with Department of Psychology, Sunway University, Malaysia (e-mail:10043214@imail.sunway.edu.my).

Ikechukwu Uba is with the Department of Human Development and Family Studies, University Putra Malaysia, Malaysia (e-mail: ubaikechukwu@yahoo.com). psychosocial developments consisting of empathy, confrontation, warmth, genuineness, management of interpersonal intimacy and clarity of expression [4]. It is crucial that young adults acquire these skills, because it helps in the understanding and acceptance of social interaction. For example, versatile interpersonal skills such as the abilities to form multiple types of relationship (e.g., hierarchical, horizontal, \& intimacy) and multiple social worlds (e.g., male and female worlds, occupational worlds, \& worlds defined by ethnicity, language, and religion) create the opportunities for young adults to adapt to the world [6]. As a result, young adults are able to socialize with their surroundings, while developing good relationship with their social support system.

The second category (Problem-Solving/Decision Making Skills (PS/DM) demonstrated one's capability to find definite solutions to a task, while decision-making skills illustrated decisions without right or wrong answers [7]. It comprises problem identification, goal setting, information seeking, time management, and conflict resolution skills. For example, most adolescents in Sri Lanka were found to use societal norms as the basis for their decision on future goals [8]. In this vein, few of them considered their own talents and capabilities before setting their future goals, this confirmed the lack of skills in relevant decision making.

The third category Physical Fitness/Health Maintenance (PF/HM), consist of nutritional maintenance, stress management, coordination, physiological aspects of sexuality and selection of leisure activity [4]. Bad choices can lead to poor health, which eventually causes death. As mentioned by Botvin [9], life skills training program can reduce adolescents' problem behaviours such as cigarette smoking, alcohol use, and drug abuse by providing the necessary information on the dangers of substance and the teaching of self-management and general social skills.

The last category (Identity Development/Purpose in Life Skills (ID/PIL) underlies the other three categories and comprises skills such as self-esteem, moral choices, self-monitoring, sex role development, emotional expression, and so on. These skills are important for the development of personal identity and emotional awareness [4]. Chang explained that young adults should be given the chance to create a sense of self, necessary in adolescent development. Too much guidance from parents stunts growth in learning and experiencing life on their own. However, without proper direction is harmful for children as they still need to learn and grow [10].

Furthermore, Larson et al. [6] argued that life skills can be obtained naturally as one continues to grow into adulthood. Even though it is possible for adolescents to update 
themselves as they develop as adolescence is a vital stage for the acquisition of life skills. This is because adolescence is a good time for the learning of new things such as language and social rules. It is also the period they develop life time attitudes and habits. As Schlegel and Barry mentioned, the stage is where adolescents embrace "social persona" [6]. Hence, it is difficult to change a person once they have adopted a persona. That is why early intervention is better than treatment.

Essentially, life skills are important during the transition of an adolescent to adulthood. Without proper skills to adapt and deal with their life, adolescents may face problems in later life, such as making wrong decisions, being isolated by society and more. As mentioned by Gazda [11], life skills are all the skills and knowledge that individuals experience besides academic skills which are essential for effective living. This means that excellence in academic skills cannot determine survival in life, if one does not have other skills necessary in life such as effective communication, decision making, self-awareness, problem solving and so on [2]-[12]. This study intends to understand the life skills development of Malaysian students with the view of identifying suitable prevention and intervention strategies for educational, clinical, counseling and skills building activities. Essentially, the study will prepare Malaysian young adults as they venture into adulthood.

\section{METHOD}

\section{A. Study Design and Participants}

Demographic form and Life Skills Development Inventory (College Form, LSI-CF) was used to measure the participants' life-skills development. Participants consisted of 500 freshmen (e.g., Pre-U, A-Levels, \& first year degree) from 5 universities around Subang Jaya area, Malaysia (i.e., Segi College, Sunway University, Taylors University, Monash University, \& INTI International University) aged 18-25. Sample from each university comprised of 100 students of equal gender (50 male, 50 female). The result showed that participants were $6.8 \%$ Malay, $79.6 \%$ Chinese, $8.8 \%$ Indian, and other races were $4.8 \%$. Overall, there are $3 \%$ married participants and $97 \%$ single young adults.

\section{B. Measurements}

Life-Skills. The Life-Skills Inventory-College Form (LSDI-CF) with 88 self-report items was used to measure college students' life-skills [13]. This assessment was designed for clinical and research purposes. It predicts potential skills deficits among young adults. The reliability coefficient for the scale was .93 and for each sub-scale were $.80, .82, .80$, and .82 , interpersonal communication, decision making, health maintenance and identity development respectively [5]. All the items were scored using a Likert scale of 0 to 3 , ranging from 0 completely disagree to 3 completely agree. Demographic form was administered together with the LSDI-CF questionnaire. Participants were required to answer questions such as age, gender, race and ethnicity.

\section{Procedure}

Ethical approval was obtained to ensure the compliance with ethical procedures before the research process began. The researcher selected five universities in Subang Jaya area with English language as a medium of instruction. One hundred participants were sampled from each university to meet the total of 500 participants. The research assistants approached the students in their university were their participation was solicited. The survey booklet was given to each participant; this consisted of the information about the study, the LSI-CF scale, and the demographic form. After the participants completed the survey form, a small gift was given by the assistants as a token of appreciation for their participation and time. All the collected data was entered into SPSS version 20 to calculate the descriptive and inferential statistics. T-test was run to examine gender differences in the four subscales of life skills development.

\section{RESULTS}

Each subscale was summed up and averaged, because of the number of questions in each scale. As shown in Table I, the mean of each subscale includes the skills the participants have the most. Overall, the results indicated that Interpersonal Communications/Human Relations Skills (IPC/HR) has the highest mean, $M=[1.90]$ followed by Identity Development/Purpose in Life Skills (ID/PIL), $M=$ [1.83], Problem-Solving/Decision-Making Skills (PS/DM), $M=[1.82]$, and Physical Fitness/Health Maintenance Skills $(\mathrm{PF} / \mathrm{HM}), M=[1.80]$.

TABLE I: THE MEAN AND STANDARD DEVIATION OF SCORE OF FOUR SUBSCALE LSI-CF

\begin{tabular}{ccl}
\hline \hline Subscales & M & SD \\
\hline IPC/HR & 1.90 & .32 \\
PS/DM & 1.82 & .35 \\
PF/HM & 1.80 & .32 \\
ID/PIL & 1.83 & .33 \\
\hline \hline
\end{tabular}

Note: IPC/HR (Interpersonal Communications/Human Relations Skills), PS/DM (Problem-Solving/Decision-Making Skills), PF/HM (Physical Fitness/Health Maintenance Skills), ID/PIL (Identity Development/Purpose in Life Skills).

TABLE II: COMPARISON OF GENDER WITH THE FOUR SUBSCALES OF LSI-CF

\begin{tabular}{lccccccc}
\hline \multicolumn{7}{l}{ Male (250) } & \multicolumn{2}{l}{$\begin{array}{l}\text { Female } \\
(250)\end{array}$} & & & & \\
\hline & $M$ & $S D$ & $M$ & $S D$ & $t(498$ & $p$ & $\begin{array}{r}\text { Cohen' } \\
\text { s d }\end{array}$ \\
\cline { 2 - 8 } IPC/HR & 1.87 & .33 & 1.91 & .30 & -1.42 & .27 & 0.004 \\
PS/DM & 1.84 & .36 & 1.80 & .34 & 1.58 & .56 & 0.005 \\
PF/HM & 1.81 & .34 & 1.78 & .29 & 1.05 & .01 & 0.002 \\
ID/PIL & 1.83 & .33 & 1.83 & .32 & -.09 & .86 & 0.000
\end{tabular}

Note: IPC/HR (Interpersonal Communications/Human Relations Skills), PS/DM (Problem-Solving/Decision-Making Skills), PF/HM (Physical Fitness/Health Maintenance Skills), ID/PIL (Identity Development/Purpose in Life Skills).

As for the result in Table II, independent sample t-test was used to investigate the difference among gender with the LSI-CF subscale. From the results, significant gender difference was found only in Physical Fitness/Health 
Maintenance Skills (PF/HM) subscale, $M s=$ [1.81], [1.78], $S D s=$ [.34], [.29]; $t(498)=1.051, p<.05$ ( $p=.009)$. The magnitude of the differences in the means (mean difference $=.030,95 \% \mathrm{CI}:-0.026$ to .0860 ) was small (eta squared $=0.002$ ). Hence, it shows that the difference between male and female must be interpreted with caution.

\section{DISCUSSION}

The aims of this study is to understand the life skills development of Malaysian students with the view of identifying suitable prevention and intervention strategies for educational and clinical purposes, such as counseling interventions and skills building activities. From the results, it can be concluded that most students has developed Interpersonal Communications/Human Relations Skills (IPC/HR). Since young, children are trained to be social beings. This is essential in a diverse country like Malaysia, as the society needs to empathize and understand the religion and cultures of others in the country.

The lowest mean was Physical Fitness/Health Maintenance Skills ( $\mathrm{PF} / \mathrm{HM}$ ) which is not surprising as the participants were chosen from urban institutions. Children in the city tend to stay at home more because they perceive the outside world as dangerous. Hence, they exercise less. Since the participants are students, they become stressed easily especially during assignments or examination time. Thus, the result might be influenced by the students' circumstances at the time of the survey. However, these results showed that experts should focus more on social skills especially for students as it is important for them to have healthy lifestyles. As Botvin [9] mentioned, adolescents with the necessary skills can actually reduce their rate of problem behaviours such as alcohol usage, drug abuse, self-management and general social skills. Therefore, intervention is necessary to help students have better lifestyles as bad choice can affect their life course.

On a different note, the study found a significant difference among genders in Physical Fitness/Health Maintenance Skills (PF/HM). This could be because males are more active than female which encourages them to exercise more. Moreover, males these days are more conscious about their body weight and shape which could also be the reason for this result. However, the effect size is small, so the result must be interpreted with caution. Hence, more research should be conducted to validate the finding.

There are strengths and limitations in this study. This study is one of the few studies done in Malaysia to investigate the life skills of Malaysian young adults. Besides, the sample for this study is large and diverse. Following these findings, Malaysian experts can use the findings as a guide in the identification of suitable interventions and areas of skills.

However, the study is limited in the sense that respondents were mostly sampled from urban areas. Hence, the life skills development for urban and rural areas might be different as Malaysia has a wide range society. Similarly, this study only focused on young adults from Subang Jaya areas which may not represent the whole Malaysia. More research therefore needs to be conducted across Malaysia to confirm or reject the findings of the study.
Nevertheless, researchers can use this study as a guide suitable prevention and intervention, such as seminar, or activities on physical fitness and health maintenance among university students. The study also offered information on gender differences in life skills developments. This can help specific genders when planning programmes. Researchers may also use this study as a comparisons and guideline for future studies in this area.

\section{CONCLUSION}

Generally, life skills are essential skills needed for children especially adolescents in their preparation for adult. According to Picklesimer [5], there are four categories of life skills which are Interpersonal Communications/Human Relations Skills (IPC/HR), Identity Development/Purpose in Life Skills, Problem-Solving/Decision-Making Skills (PS/DM), and Physical Fitness/Health Maintenance Skills $(\mathrm{PF} / \mathrm{HM})$ that are essential for development. The aims of this study is to understand the life skills development of Malaysian students, to identify suitable prevention and intervention strategies for educational and clinical purposes such as counseling interventions and skills building activities.

From the results, it can be concluded that most students has developed Interpersonal Communications/Human Relations Skills (IPC/HR) because of the natural instinct to socialize. Physical Fitness/Health Maintenance Skills (PF/HM) is higher for males than female which could be because males are more active than females exercise wise. Results from this study can be used to provide suitable prevention and interventions for university students. Researchers can also use this study as a comparisons and guideline for future studies in this area. Nonetheless, more studies need to be conducted across Malaysia on this areas as more consistent results is better in developing suitable interventions for adolescents..

\section{REFERENCES}

[1] C. L. Packer. (2006). [Online]. Available: http://athenaeum.libs.uga.edu/bitstream/handle/10724/9270/packer_ca therine_1_200608_phd.pdf?sequence=1.

[2] World Health Organization (WHO), Life Skills Education for Children and Adolescents in Schools: Introduction and Guidelines to Facilitate the Development and Implementation of Life Skills Programmes, Geneva, Switzerland: World Health Organization, 1997.

[3] World Health Organization (WHO), Violence Prevention the Evidence: Preventing Violence by Developing Life Skills in Children and Adolescents, Geneva, Switzerland: World Health Organization, 2009.

[4] D. K. Brooks, A Life-Skills Taxonomy: Defining Elements of Effective Functioning with the Use of Delphi Technique, The University of Georgia, USA, 1984

[5] B. K. Picklesimer, The Development and Evaluation of the Life-Skills Development Inventory-College Form, The University of Georgia, USA, 1991.

[6] R. W. Larson, S. Wilson, B. B. Brown, and Jr. F. F. Furstenberg, "Changes in adolescents' interpersonal experiences: Are they being prepared for adult relationships in the twenty-first century?" Journal of Research on Adolescence, vol. 12, no. 1, pp. 31-68, 2002.

[7] B. Fishoff, "For those condemned to study the past: Reflections of historical judgment," in New Directions for Methodology of Behavioral Science: Fallible Judgment in Behavioral Research.

[8] R. A. Sweden and D. W. Fiske, Ed. San Francisco: Jossey-Bass, 1980, pp. 79-93.

[9] N. Thalagala, National Survey on Emerging Issues Among Adolescents in Sri Lanka, UNICEF, Medistat Research (Pvt) Limited, 2004. 
[10] G. J. Botvin, "Preventing adolescent drug abuse through life skills training: Theory, evidence of effectiveness, and implementation issues," in Improving Prevention Effectiveness.

[11] W. B. Hansen, S. M. Giles, and M. F. Kenney, Ed., Greensboreo, NC: Tanglewood Research, Inc, 2000, pp. 141-154.

[12] M. Chang. Cultural differences in parenting styles and their effects on teens' self-esteem, perceived parental relationship satisfaction, and self-satisfaction. Honors Theses. [Online]. 85. pp. 1-46. Available: http://repository.cmu.edu/hsshonors/85

[13] G. M. Gazda, Group Counseling: A developmental Approach, 4th ed. Boston: Allyn and Bacon, 1989.

[14] G. M. Gazda, "Social/life-skills training: An intervention that is revolutionizing counseling and therapy," NYSACD Journal, pp. 9-17, 1992.

[15] B. K. Picklesimer and G. M. Gazda, Life-Skills Development Inventory-College, 1996.

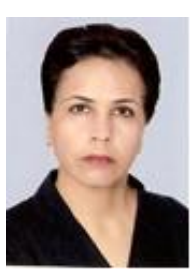

S. Mofrad is a lecturer at Sunway University in Malaysia, and received her PhD in Psychology of Child Development from Universiti Putra Malaysia. She did her graduate work at Tehran Institute of Psychiatry and her undergraduate work at Shiraz University. She began her career at the Health Center in Boushehr University, Iran as a clinical psychologist since 1991. Her research has focused on a variety of topics relevant to parent-child relationships and child mental health. In general her work reflects an interest in studying what is good and healthy for families.

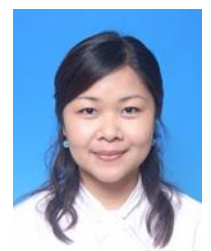

K. F. Chee is a lecturer from Sunway University, who received her Master in Counselling Psychology and Bachelor in Psychology from National University of Malaysia. She is a Registered Counsellor and did her clinical practice in mental health setting since 2002. She began her career as a Lecturer since 2005 . Her research has focused on a variety of topics relevant to counselling psychology and mental health. In general her work reflects an interest in studying counselling related and mental health issue. She registered as counsellor KB 00441.

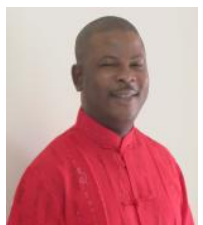

Ikechukwu Uba is a developmental psychologist from University Putra Malaysia. He is majored in Human Development. His research interest revolves around human developmental issues across the life span. He has authored and co-authored many academic papers, books and book chapters. 